\title{
POU genes are expressed during the formation of individual ganglia of the cephalopod central nervous system
}

Tim Wollesen ${ }^{1 *}$, Carmel McDougall ${ }^{2}$, Bernard M Degnan² and Andreas Wanninger ${ }^{1}$

\begin{abstract}
Background: Among the Lophotrochozoa, cephalopods possess the highest degree of central nervous system (CNS) centralization and complexity. Although the anatomy of the developing cephalopod CNS has been investigated, the developmental mechanisms underlying brain development and evolution are unknown. POU genes encode key transcription factors controlling nervous system development in a range of bilaterian species, including lophotrochozoans. In this study, we investigate the expression of POU genes during early development of the pygmy squid Idiosepius notoides and make comparisons with other bilaterians to reveal whether these genes have conserved or divergent roles during CNS development in this species.

Results: POU2, POU3, POU4 and POU6 orthologs were identified in transcriptomes derived from developmental stages and adult brain tissue of $I$. notoides. All four POU gene orthologs are expressed in different spatiotemporal combinations in the early embryo. Ino-POU2 is expressed in the gills and the palliovisceral, pedal, and optic ganglia of stage 19 to 20 embryos, whereas the cerebral and palliovisceral ganglia express Ino-POU3. Ino-POU4 is expressed in the optic and palliovisceral ganglia and the arms/intrabrachial ganglia of stage 19 to 20 individuals. Ino-POU6 is expressed in the palliovisceral ganglia during early development. In stage 25 embryos expression domains include the intrabrachial ganglia (Ino-POU3) and the pedal ganglia (Ino-POU6). All four POU genes are strongly expressed in large areas of the brain of stage 24 to 26 individuals. Expression could not be detected in late prehatching embryos (approximately stage 27 to 30 ).

Conclusions: The expression of four POU genes in unique spatiotemporal combinations during early neurogenesis and sensory organ development of $I$. notoides suggests that they fulfill distinct tasks during early brain development. Comparisons with other bilaterian species reveal that POU gene expression is associated with anteriormost neural structures, even between animals for which these structures are unlikely to be homologous. Within lophotrochozoans, POU3 and POU4 are the only two genes that have been comparatively investigated. Their expression patterns are broadly similar, indicating that the increased complexity of the cephalopod brain is likely due to other unknown factors.
\end{abstract}

Keywords: brain, complex, evolution, development, homeobox genes, invertebrate, Lophotrochozoa, mollusk, ontogeny

\footnotetext{
* Correspondence: tim.wollesen@univie.ac.at

${ }^{1}$ Department of Integrative Zoology, Faculty of Sciences, University of Vienna,

Althanstr. 14, 1090 Vienna, Austria

Full list of author information is available at the end of the article
} 


\section{Background}

Cephalopod mollusks such as squids, cuttlefish, octopuses, and nautiluses are one of the most fascinating invertebrate groups with respect to their cognitive abilities and behavioral repertoire [1-3]. Although coleoid cephalopods, that is, all cephalopods except for nautiluses, exhibit a number of molluscan plesiomorphies, they also possess unique (autapomorphic) features such as a highly centralized CNS (Figure 1), which is composed of more than 35 individual brain lobes in some species. Intricately connected to sensory and motor systems, the CNS is arranged around the esophagus with perikarya surrounding the neuropil (Figure 1; [4]). The adult brains of Octopus vulgaris and Loligo vulgaris belong to the invertebrate brains that have been best investigated by means of classical histological techniques and investigations on the developing brains commenced in the 1970s (L. vulgaris [5]; O. vulgaris [6]; Sepioteuthis lessoniana [7]; Idiosepius paradoxus [8]; Nautilus pompilius [9], reviewed in [10]). Only recently, the spatiotemporal distribution of certain neuronal markers was investigated in detail for a limited number of cephalopod species. These studies revealed that selected neuropeptides and neurotransmitters are expressed during early CNS development and thus appear to play a role during early neurogenesis [11-16]. They also suggest that certain neuronal populations that contain these substances might be homologous among coleoids $[12,13,16]$.

Although coleoid cephalopods are ideal systems to investigate the molecular underpinnings of the development of complex invertebrate brains, little is known about genes that regulate the establishment of the cephalopod CNS. One group of genes that is involved in neurogenesis and that is well studied for ecdysozoan and vertebrate model systems (but less so for lophotrochozoans, except for a few isolated accounts on gastropod mollusks and the annelid model Platynereis dumerilii) is the POU gene family. POU genes are a metazoan-specific class of homeobox genes that encode transcription factors $[17,18]$. Detailed studies on model organisms such as fruit fly, frog, mouse, or rat suggested that these genes orchestrate the proper spatiotemporal expression of a plethora of genes involved in crucial developmental processes (Table 1, [19,20]). While POU gene orthologs are consistently expressed in the nervous system of adults and developmental stages of a number of phylogenetically distant taxa such as acoels, cnidarians, insects, tunicates and fishes (Table 1; [19]), expression domains also comprise other epithelia such as the cephalochordate ectodermal sensory cells and gill slits, the pronephridial duct of the zebrafish, and the statocysts and gonads of hydrozoans (Table 1). Functional
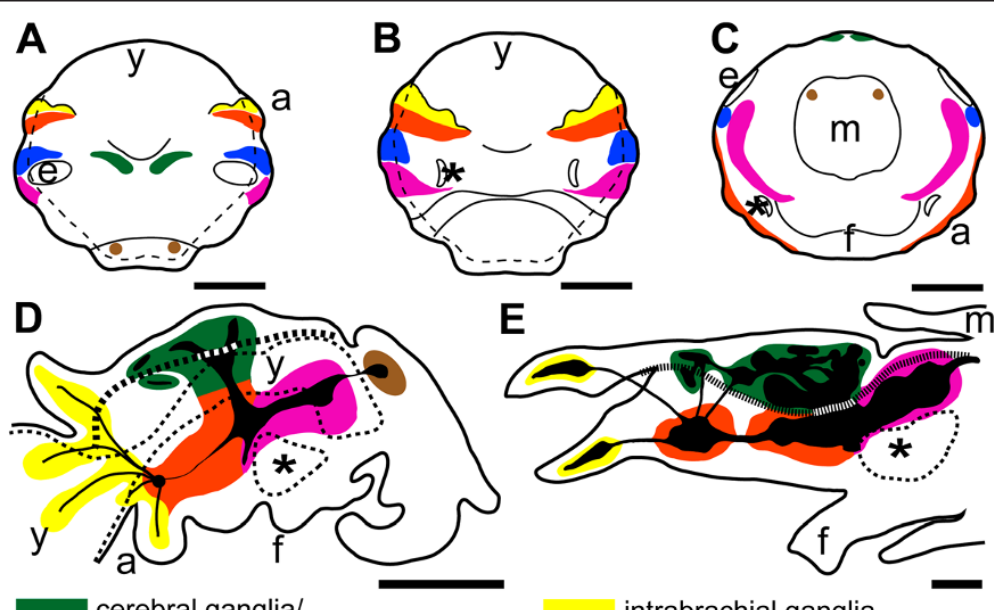

$\mathrm{E}$
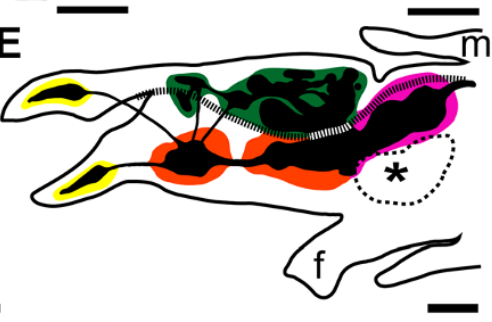

cerebral ganglia/ supraesophageal mass

pedal ganglia/ anterior \& middle subesophageal mass

palliovisceral ganglia/ posterior subesophagea mass

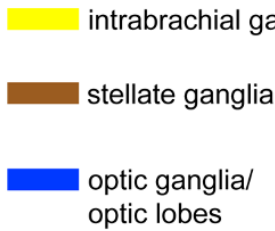

Figure 1 Sketch drawings highlighting the development of individual ganglia into a centralized brain in I. notoides. In stages older than stage 19, the neuropil (black) consolidates in the center of various brain lobes. (A) Dorsal view of a stage 19 embryo (anterior faces up). (B) Ventral view of a stage 19 embryo (anterior faces up). (C) Posterior view of a stage 19 embryo (dorsal faces up). (D) Sagittal section along the midline of a stage 23 embryo (anterior faces to the left). (E) Sagittal section along the midline of the anterior body regions of a stage 30 hatchling (anterior faces to the left). The esophagus is marked by a thick dashed line and the internal and external yolk portions are outlined by a thinner dashed line in $D$ and $E$. The statocysts are marked by asterisks. Abbreviations: a, arm; e, eye; f, funnel; m, mantle; y, yolk. Modified from $[8,12]$. Scale bars $150 \mu \mathrm{m}$. 
Table 1 Metazoan POU gene expression domains with focus on lophotrochozoan taxa as revealed by in situ hybridization experiments

Acoela

Neochildia fusca

Cnidaria

Craspedacusta sowerbyi

Aurelia spec.

\section{LOPHOTROCHOZOA}

Gastropoda

H. asinina

\section{Annelida}

P. dumerilii

\section{ECDYSOZOA}

Drosophila melanogaster

Caenorhabditis elegans
A: (BRN-1): stem neoblasts?, neurons, intraepidermal gland cells

A: POU4 (BRN-3): neurons

A: POU4f1: bell margin in statocysts between tentacles

A: POU4f2: bell margin in statocysts between tentacles, gonads

A: POU4f3: close to center of bell quadrants, gastric cavity

A: POU6: statocysts, gonads

A: POU1 (PIT1): rhopalia

D: trochophore: POU3: 2 bilateral ectodermal (mucus) cells in centroposterior foot anlage, two cells in anterolateral foot anlage

Pre-torsional veliger: 2 bilateral ectodermal (mucus) cells in centroposterior foot (close to operculum)

Post-torsional veliger: 2 bilateral ectodermal (mucus) cells in centroposterior foot (close to operculum), pleuropedal, cerebral, esophageal ganglia, branchial ganglia, dorsoposterior region of visceral mass, statocysts, radular sac anlage

A: POU3: cerebral and pleuropedal ganglia, epipodial fringe, tentacle, eye, gill, muscle

D: trochophore: POU4: single cell in prospective mantle edge of trochophore larva), bilateral pair of ventral ectodermal cells in anterocentral region of foot anlage +2 additional cells later

Pre-torsional veliger: anterocentral ectoderm of foot, no expression in mantle, additional pair of cells in lateromedian ectoderm of foot

Post-torsional veliger: ventral ectoderm of foot + lateral expansion of anterocentral cells, cells in vicinity of prospective eyes, 2 territories on left side of cephalopedal and visceropallial junction (vicinity of esophageal ganglia), cells close to mouth, statocysts, vicinity of ctenidial and osphradial anlagen

A: POU4: cerebral and pleuropedal ganglia, epipodial fringe, eye, tentacle, gill

A: POU4 (BRN3): expression in longitudinal columns which are segmentally clustered along regenerated ventral nerve cord and in cells in developing parapodia (parapodial ganglia?)

D: POU2 (PDM-1 (POU-19), PDM-2 (POU-29)): neuroectoderm, (peripheral) sensory organs

D: POU3 (CF1a): ectodermal segmental expression, tracheal cells, mesectodermal cells arranged along longitudinal ventral midline of embryo

D: POU4 (I-POU): supraesophageal ganglia and ventral nerve cord

D: POU2 (CEH-18): muscles and epidermis

A: gonadal sheath cells

D: POU3 (CEH-6): neurons

D: POU4 (UNC-86): neural precursor cells

A: neurons 
Table 1 Metazoan POU gene expression domains with focus on lophotrochozoan taxa as revealed by in situ hybridization experiments (Continued)

\begin{tabular}{|c|c|}
\hline \multicolumn{2}{|l|}{ DEUTEROSTOMIA } \\
\hline Ciona intestinalis (Tunicata) & $\begin{array}{l}\text { D: embryo: POU4: neural precursor cells in PNS. Restricted to } \\
\text { posterior sensory vesicle and motoneurons of visceral ganglion } \\
\text { in CNS }\end{array}$ \\
\hline Branchiostoma floridae (Cephalochordata) & $\begin{array}{l}\text { D: embryo and larva: POU4: anteriormost neural plate and in } \\
\text { bilateral ectodermal (sensory?) cells of neurula. Subsequently, } \\
\text { expression in motoneurons behind posterior cerebral vesicle } \\
\text { and in segmentally arranged motoneurons in hindbrain, in } \\
\text { rostrum and epidermal sensory cells close to mouth. }\end{array}$ \\
\hline Branchiostoma floridae (Cephalochordata) & $\begin{array}{l}\text { D: embryo and larva: POU3: expression in dorsal epiblast and } \\
\text { entire neural plate except a portion close to cerebral vesicle. } \\
\text { Expression in primordium of gill slits, pharynx and left } \\
\text { Hatschek's diverticulum. }\end{array}$ \\
\hline Danio rerio (Vertebrata) ${ }^{a}$ & $\begin{array}{l}\text { D: embryo: POU3: expression in fore-, mid-, and hindbrain, } \\
\text { in spinal cord and pronephric duct }\end{array}$ \\
\hline \multirow[t]{3}{*}{ Xenopus laevis } & $\begin{array}{l}\text { D: POU1: neural fold stage: anterior neural plate; tailbud } \\
\text { stage: anterodorsal portion (eye and brain); A: skin and brain }\end{array}$ \\
\hline & $\begin{array}{l}\text { D: POU2: neurula stage: anterior nerve cord; tailbud stage: } \\
\text { anterodosal region; A: adults in kidney and brain }\end{array}$ \\
\hline & D: POU3: neurula stage: brain and spinal cord, auditory vesicle \\
\hline \multirow[t]{3}{*}{ Rattus norvegicus } & $\begin{array}{l}\text { A: POU1 (PIT-1), POU2 (OCT-2), POU3 (BRN-2), POU4 (BRN-3), } \\
\text { TST-1, OCT-1: nervous system }\end{array}$ \\
\hline & D: POU6 (BRN-5): developing CNS, spinal cord \\
\hline & A: brain, kidney, lung, heart, testis, pituitary \\
\hline
\end{tabular}

${ }^{a}$ See [19] for an exhaustive list on POU gene expression domains in developing and adult vertebrates.

studies suggest that $P O U$ genes are employed in gastrulation and apoptosis in vertebrates as well as in segmentation and specification of neural precursor cells in the fruit fly [19]. In contrast, only sparse information is available on $P O U$ gene expression in the Lophotrochozoa. Although few studies identified $P O U$ genes as being expressed in various tissues by means of RT-PCR or immunohistochemistry [21-23], studies by in situ hybridization on the spatiotemporal expression in lophotrochozoans only exist on the gastropod Haliotis asinina (POU3 and POU4) and the annelid P. dumerilii (POU4) (Table 1; [24-27]). In larval developmental stages of $H$. asinina, POU3 is expressed in the anlagen of the CNS but also in non-neural domains such as mucus cells of the foot, a portion of the visceral mass, the statocysts, and the anlagen of the radular sac (Table 1; [25]). In adults, expression domains comprise the cerebral and pleuropedal ganglia, epipodial tentacles, tentacles, eyes, gills, and muscles (Table 1; [24]). POU4 is expressed in different sets of ectodermal cells in the foot, in the vicinity of the esophageal ganglia, and in the statocysts of the larvae of $H$. asinina (Table 1 ; [26]). Moreover, POU4 is expressed in cells in the mantle, in cells in the vicinity of the eyes and the ctenidial and osphradial anlagen of developmental stages of $H$. asinina. In adults, POU4 expression domains resemble those of POU3 and include the cerebral and pleuropedal ganglia, the epipodial tentacles, eyes, tentacles, and gills (Table 1; [24]). In the annelid P. dumerilii POU4 (Brn3) is expressed in the neuroectoderm of the ventral nerve cord and probably in neurons of the parapodial ganglia (Table 1; [27]). Interestingly, a recent EST analysis of stage 16 to 28 specimens of the cuttlefish Sepia officinalis did not reveal POU gene transcripts [28]. The authors suggested that, besides possible technical reasons, $P O U$ genes might solely be expressed in earlier developmental stages, that is, stages that do not yet exhibit anlagen of the nervous system ([28], cf. [11,29] for staging of specimens).

In order to facilitate a comparative approach, the transcriptomes of whole animals of prehatching developmental stages as well as of the isolated adult CNS of the pygmy squid $I$. notoides were screened for candidate POU orthologs. In this study, expression patterns of Ino-POU2, Ino-POU3, Ino-POU4, and Ino-POU6 are described for developmental stages of the pygmy squid $I$. notoides to determine where POU genes are expressed during the development of a coleoid cephalopod. This work represents the most comprehensive study on $P O U$ genes in lophotrochozoans and offers insights into their expression in an invertebrate with a highly centralized and complex brain.

\section{Methods}

Collection, RNA extraction, and fixation of animals

Adults of the pygmy squid I. notoides were dip-netted in the seagrass beds of Moreton Bay, Queensland, Australia. 
Embryos were cultured and staged as described previously $[12,47]$. After the removal of egg jelly and chorion, the RNA of approximately 300 specimens covering developmental stages from the freshly laid zygotes to posthatching individuals, that is, stages 0 to 30 and hatchlings [47], was extracted using TriReagent according to the manufacturer's instructions (Astral Scientific Pty. Ltd., Caringbah, Australia). For adult squids, RNA was extracted from the entire CNS of seven adults. Stage 19 to 30 individuals were fixed for in situ hybridization experiments (see [12,47] for staging criteria).

\section{RNAseq and transcriptome assembly}

RNA of developmental stages was sequenced by 454 technology; RNA retrieved from the entire adult central nervous system was sequenced by Illumina technology (Eurofins, Ebersberg, Germany). A total of 588,878 reads with an average read length of $377 \mathrm{bp}$ were obtained from the 454 sequencing. These reads were subsequently filtered (rRNA removal), and adapter and low quality sequences were trimmed, normalized, and assembled de novo by Eurofins. The 38,267,214 Illumina reads (100-bp long, paired-end) were filtered (rRNA removal), and adapter and low quality sequences trimmed, normalized, and assembled de novo into contigs with the assembler Trinity [48] by the authors. The 454 transcriptome comprises 55,555 contigs $(\mathrm{N} 50=620)$, whereas the Illumina transcriptome comprises 166,289 contigs $(\mathrm{N} 50=977)$.

\section{Alignment and phylogenetic analysis}

Known amino acid sequences of bilaterian POU gene orthologs retrieved from NCBI were used in BLAST searches against the assembled transcriptomes. Amino acid sequences were aligned and the conserved motifs of the POU specific domain and the POU-type homeodomain were used to reconstruct trees, which were generated using Jukes-Cantor as Genetic Distance Model and Neighbor-Joining as Tree build Method implemented in the program Geneious Pro 5.5.6 (Biomatters, Auckland, New Zealand, www. geneious.com).

\section{Molecular isolation of RNA transcripts}

First-strand cDNA was synthesized by reverse transcription of RNA pooled from different developmental stages using the First strand cDNA Synthesis Kit for rt-PCR (Roche Diagnostics GmbH, Mannheim, Germany). Genespecific primers were designed from identified $P O U$ genes and transcripts were amplified via standard PCR. PCR products were size-fractioned by gel electrophoresis, and bands of the expected length were excised. Gel bands were cleaned up using a QIAquick Gel Extraction Kit (Qiagen, Hilden, Germany). Cleaned-up products were cloned by insertion into pGEM-T Easy Vectors (Promega, Mannheim, Germany) and plasmid minipreps were grown overnight. Finally, plasmids were sent for sequencing, and orthologs of Ino-POU2, Ino-POU3, InoPOU4, and Ino-POU6 were identified using the BLASTx algorithm screening the database of the National Center for Biotechnology Information (NCBI).

\section{Probe syntheses and whole-mount in situ hybridization}

The probe template was amplified from the miniprepped plasmids via standard PCR using M13 forward and reverse primers, and in vitro transcription reactions were performed with these templates, digoxigenin-UTP (DIG RNA Labeling Kit, Roche Diagnostics), and SP6 polymerase (Roche Diagnostics $\mathrm{GmbH}$ ) for the syntheses of antisense riboprobes, according to the manufacturer's instructions. Whole-mount in situ hybridization experiments were carried out as described previously [12]. Briefly, developmental stages were rehydrated into PBT (PBS $+0.1 \%$ Tween-20). They were treated with Proteinase-K $\left(20 \mathrm{mg} / \mathrm{ml}\right.$ in PBT at $37^{\circ} \mathrm{C}$ for $\left.15 \mathrm{~min}\right)$ and prehybridized in hybridization buffer for $4 \mathrm{~h}$ at 55 to $65^{\circ} \mathrm{C}$. Hybridization with a probe concentration of 0.5 to $1 \mu \mathrm{g} / \mathrm{ml}$ was carried out overnight at 55 to $65^{\circ} \mathrm{C}$. For each gene, a minimum of 20 individuals per stage was investigated. In addition, negative controls were carried out with sense probes for all genes and developmental stages. After hybridization, selected developmental stages were embedded in a solution of gelatin-ovalbumin, vibratome-sectioned, and mounted on glass slides in order to facilitate the identification of expression domains in the individual brain lobes. In addition, the majority of whole-mount preparations were cleared in a solution of benzyl-benzoate and benzyl alcohol, analyzed, and the results were documented with a Nikon Eclipse E800 microscope. If necessary, images were processed with Adobe Photoshop 9.0.2 software (San Jose, CA, USA) to adjust contrast and brightness.

\section{Statement of ethical approval}

Animals were collected, anesthetized, and fixed according to internationally recognized standards (University of Queensland Animal Welfare Permit No. 158/09 'The cultivation of Idiosepius (pygmy squid) for studies in developmental biology' to BMD).

\section{Results}

\section{POU gene orthologs and phylogenetic analysis}

Both I. notoides developmental and brain transcriptomes contain assembled transcripts encoding four POU homeodomain transcription factors of varying lengths. Ino-POU2, Ino-POU3, Ino-POU4 and Ino-POU6 were recovered as partial sequences of 158, 190, 139 and 163 amino acids (aa) in length, respectively (Figure 2). The coding sequences comprise an N-terminal POU-specific domain and a C-terminal POU-type homeodomain, which are separated by a linker region (Figure 2). All four Ino-POU amino acid 


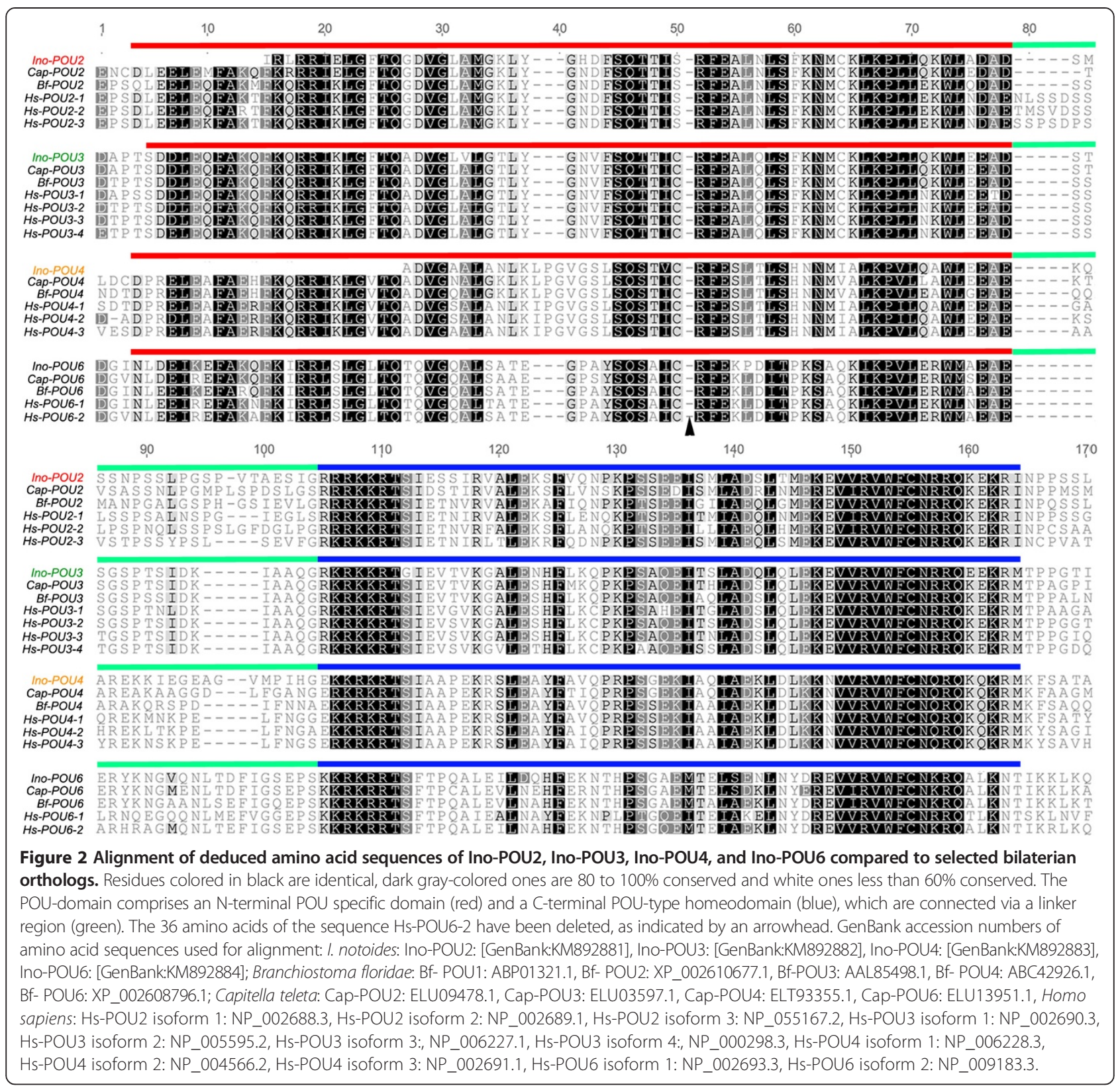

sequences cluster with their bilaterian orthologs, as revealed by our phylogenetic analysis (Figure 3).

\section{Overall anatomy and ontogeny of the central nervous system in I. notoides}

The ontogeny of the CNS of I. notoides and its sister species $I$. paradoxus was described previously $[8,12]$. In stage 17 to 18 embryos, neuroblasts ingress, migrate from the ectoderm, and coalesce to establish the anlagen of the future paired cerebral, pedal, palliovisceral, optic, stellate, and intrabrachial ganglia during early development, when the ectodermal layer covers the yolk syncytium (Figure 1A, $\mathrm{B}$ and $\mathrm{C} ;[8,12])$. Successively, the individual ganglia develop neuropilar regions with the palliovisceral ganglia exhibiting the most prominent neuropil during early development (Figure 1D). Traditionally, all ganglia are named 'lobes' after stage 23. At this stage, the palliovisceral ganglia develop into the posterior subesophageal and the periesophageal mass (Figure 1D and E), the pedal ganglia develop into the anterior and middle subesophageal mass, and the supraesophageal mass develops from the cerebral ganglia. These masses comprise various individual lobes (up to 35 in some coleoid cephalopods), which are subject to increased neuropilar growth and a relative decrease of perikarya during subsequent development. The adult CNS of I. notoides resembles that of its sister species I. paradoxus $[8,12,13,49]$. It 


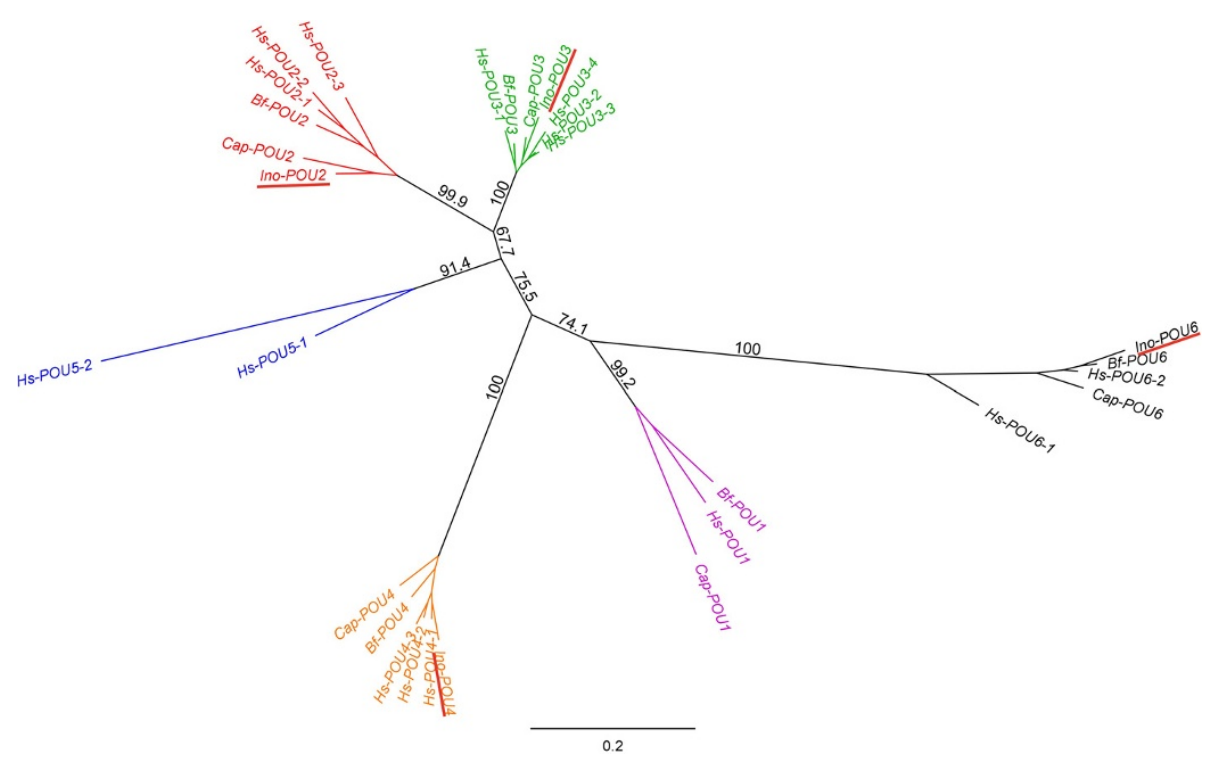

Figure 3 Neighbor-joining consensus tree of the POU gene family including deduced amino acid sequences of POU1 (pink), POU2 (red), POU3 (green), POU4 (orange), POU5 (blue), and POU6 (black) of $I$. notoides and selected bilaterians. All subfamilies are robustly supported. Tree nodes are supported by bootstrap values of 1,000 replicates and the consensus support (\%). Branch length of the tree represents amino acid substitution per site (see scale bar for measurement). GenBank accession numbers of all sequences are itemized in caption of Figure 2 or mentioned as follows: Capitella telata: Cap-POU1: ELT90027.1, Cap-POU5: ELT90025.1; Branchiostoma floridae: Bf-POU1: ABP01321.1; Homo sapiens: Hs-POU1: NP_000297.1; Hs-POU5 isoform 1: NP_002692.2, Hs-POU5 isoform 2: NP_694948.1.

is composed of a central brain and two laterally attached optic lobes that process the visual stimuli from the laterally attached eyes. The brain is composed of a supraesophageal and a subesophageal mass, which are divided by the esophagus and are laterally connected with each other (Figure 1). The periesophageal mass is located ventrally to the posterior subesophageal mass and is often difficult to distinguish from the middle and posterior subesophageal mass shown in Figure 1E.

\section{POU gene expression}

Gene expression patterns of stage 19 to 30 (hatchlings) individuals were analyzed, and the stages in which expression patterns change are presented.

\section{Ino-POU2 expression}

Stage 19 embryos express Ino-POU2 in the anlagen of the gills (Figures $4 \mathrm{~A}$ and 5). In subsequent developmental stages Ino-POU2 is also expressed in the palliovisceral, pedal, and optic ganglia as well as in the posterior mantle (Figure 4B). Expression gains in intensity in stages 21 to 22 individuals, while a diffuse global expression was observed in the animal with exception of the arms (Figure 4C). The strongest Ino-POU2-expression was observed in the palliovisceral and pedal ganglia and the eyes (Figure 4C). This situation remains similar in stage 24 individuals, whose anterior, middle and posterior subesophageal masses express Ino-POU2, while a few individual lobes of the supraesophageal mass exhibit weak staining
(Figure 4D). This changes in stage 25 individuals, which strongly express Ino-POU2 throughout the brain and also at a lower level in the optic lobes (Figure 4E). In stage 25 individuals, and subsequent developmental stages, Ino-POU2 is expressed in the supraesophageal, periesophageal, and subesophageal masses (Figure 4E,F,G and $\mathrm{H})$. In the supraesophageal mass, the anterior basal and posterior basal lobes express Ino-POU2 (Figure 4F,G). Lobes of the vertical lobe complex, such as the superior frontal lobe and the subvertical lobe, also express InoPOU2 (Figure 4G). The optic lobes also exhibit slight expression of Ino-POU2 (Figure 4F). Ino-POU2-expression domains of stage 27 individuals resemble those of stage 26 individuals (Figure 4H); however, later prehatching developmental stages cease to express Ino-POU2.

\section{Ino-POU3 expression}

Stage 19 embryos express Ino-POU3 in the distal portion of both cerebral ganglia and the anterior palliovisceral ganglia (Figures 6A and 5). In addition, Ino-POU3 expression is present in two circular domains in the mantle (Figure 6B). Expression in the palliovisceral ganglia gains in intensity in subsequent developmental stages such as stage 22, and further expression is present in the pedal ganglia and the eyes (Figure $6 \mathrm{C}$ ). The first supraesophageal expression domain appears slightly later in what are probably the anlagen of the anterior basal lobes in the cerebral ganglia (Figure 6C, lower inset). The expression domains widen during stage 24 when Ino- 


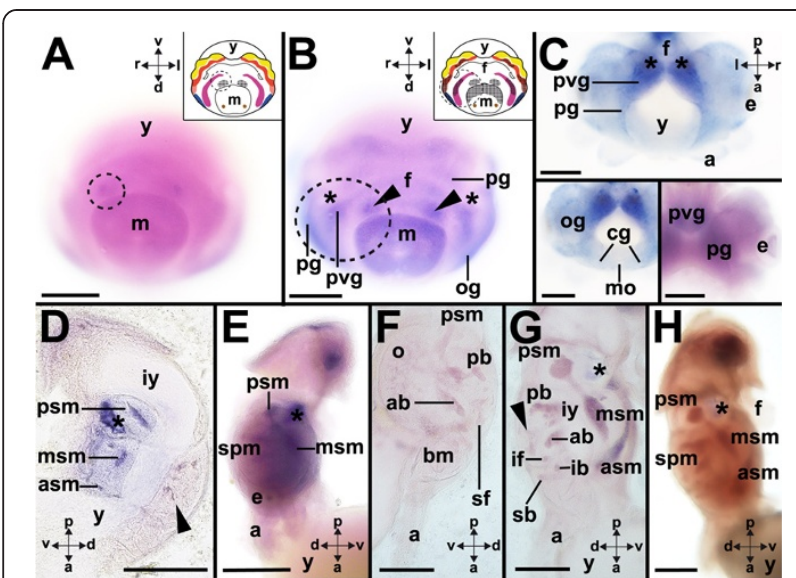

Figure 4 Ino-POU2-expression during development of $I$. notoides. Cartoons highlight Ino-POU2-expression as black checkered domains (see Figure 1 for color-code of ganglia). Dorsal (d)-ventral (v), anterior (a)-posterior (p), and left (I)-right ( $r$ ) axes indicate the orientation. (A) During stage 19 Ino-POU2 is expressed in the gills close to the mantle (m). (B) Stage 20 embryos exhibit expression in the gills (arrowheads), the posterior mantle, the palliovisceral (pvg), the pedal (pg), and the optic ganglia (og) (posteroventral view). (C) Stage 21 individuals globally express Ino-POU2 including the palliovisceral and pedal ganglia, however not in the cerebral ganglia (cg) or the funnel (upper and lower left inset). Ino-POU2 is expressed in the eyes (e) during stage 22 (lower right inset) (yolk sac removed in images). (D) During stage 24, Ino-POU2 is expressed in the anterior (asm), middle (msm), and posterior subesophageal masses (psm). Slight expression was observed in the lobes of the supraesophageal mass (arrowhead) (sagittal vibratome section). The staining in the statocyst is unspecific. (E) During stage 25, Ino-POU2 is expressed in the brain including the supraesophageal mass (spm). (F) Close-up of Ino-POU2 expression in the supraesophageal mass during stage 26. Expression domains comprise the anterior (ab) and posterior basal lobes (pb), the superior frontal lobe (sf), and the optic lobes (o) (sagittal vibratome section). (G) The expression domains of later embryos resemble the ones of stage 26 individuals (sagittal vibratome section). During stage 27 Ino-POU2 is expressed in the vertical lobe complex (arrowhead) of the supraesophageal mass. Ino-POU2 is expressed in the superior buccal (sb) and inferior buccal lobes (ib) as well as the inferior frontal lobes (if). (H) Ino-POU2 expression during stage 27. Asterisks mark the statocysts. Abbreviations: a, arm; f, funnel; iy, internal yolk; mo, mouth; y, yolk. Scale bars: A-E: $150 \mu \mathrm{m}, \mathrm{F}-\mathrm{H}: 200 \mu \mathrm{m}$.

POU3 expression is also present in large portions of the supraesophageal mass (Figure 6D,E). The posterior subesophageal mass, periesophageal mass and the peduncle lobes express Ino-POU3, in contrast to both optic lobes (Figure 6D,E). Ino-POU3 is expressed in the anterior and posterior portion of the anterior basal lobes (Figure 6E), the precommissural lobes, and the lobes of the posterior basal lobes (Figure 6E). Further expression was observed in lobes that connect to the middle subesophageal mass such as the interbasal lobes (Figure 6F). The ventral magnocellular lobes (one of the three periesophageal lobes) as well as the middle and anterior subesophageal masses also express Ino-POU3 (Figure 6G).
Ino-POU3-expression is stronger in subsequent developmental stages such as stage 25 individuals and apparent in the superior and inferior buccal lobes (Figure $6 \mathrm{H}$ ) but also the superior and inferior frontal lobe (Figure 6I). Additional lobes that express Ino-POU3 are the dorsolateral, dorsal basal, and the peduncle lobes (Figure 6I). The intrabrachial lobes of the arms also express InoPOU3 at stage 25 (Figure 6I), but not in other developmental stages (c.f. for example, Figure 6K). Ino-POU3 is expressed at a higher level in stage 26 individuals; however, no expression is found in the subvertical and vertical lobes (arrowhead in Figure 6J). Stage 26 to 30 individuals do not exhibit Ino-POU3 expression in the eyes (Figure 6K). Stage 27 individuals and older prehatching stages exhibit only weak or no Ino-POU3-expression in their brains (Figure 6K). Besides a few Ino-POU3 expressing neurons (Figure 6D) the optic lobes do not express Ino-POU3 (for example, Figure 6I,K).

\section{Ino-POU4 expression}

Ino-POU4 is expressed in the optic and palliovisceral ganglia of stage 19 individuals (Figures $7 \mathrm{~A}, \mathrm{~B}$, and 5 ). In some individuals, Ino-POU4 is expressed more weakly on the left or right side of the body (arrowhead in Figure 7A). Subsequent developmental stages such as stage 20 individuals show increased expression of Ino-POU4 in the optic and palliovisceral ganglia (Figure 7C) and also in the anlagen of the arms, that is, in the intrabrachial ganglia (Figure 7D). Stage 21 individuals exhibit slight expression of Ino-POU4 in the pedal ganglia (arrowhead in right inset of Figure 7E). Stage 22 and 23 specimens exhibit strong Ino-POU4 expression in the optic ganglia, as well as in the palliovisceral, pedal, and cerebral ganglia (Figure 7F, G). Expression in the intrabrachial ganglia could no longer be observed (Figure 7F, G). In stage 25 and 26 individuals, expression of Ino-POU4 is extended to large parts of the CNS (Figure 7H). Expression domains include all lobes of the anterior, middle, and posterior subesophageal masses (Figure $7 \mathrm{H}$ ). In addition, the lobes of the periesophageal mass and the lobes of the supraesophageal mass with exception of the vertical lobe express Ino-POU4 (Figure 7H). Subsequent developmental stages until hatchlings exhibit only faint or no Ino-POU4expression in the CNS (Figure 7I).

\section{Ino-POU6 expression}

In early developmental stages such as stage 19, Ino-POU6 is expressed in the palliovisceral ganglia (Figures $8 \mathrm{~A}$ and 5). In stage 22 individuals, Ino-POU6 is additionally expressed in the pedal ganglia (Figure 8B). Subsequent developmental stages, such as stage 23 , show strong expression in their pedal and palliovisceral ganglia (Figure 8C,D). Faint or no expression is present in the supraesophageal mass of stage 23 individuals (Figure 8E). Stage 25, 26, and 


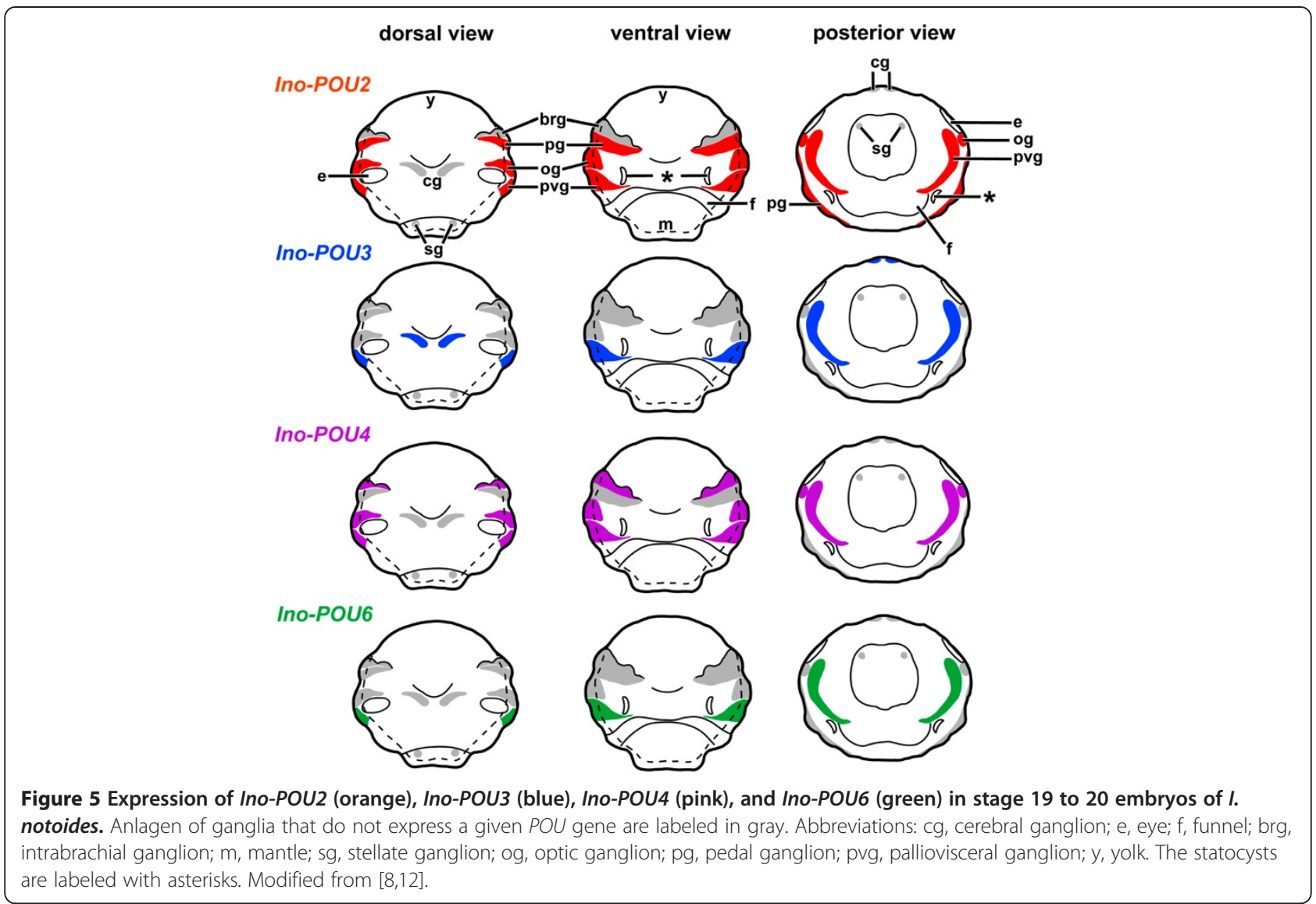

stage 27 individuals are characterized by strong expression of Ino-POU6 in large parts of the CNS (Figure 8F, G, H, I and J). Lobes of the anterior, middle, and posterior subesophageal masses and the periesophageal mass exhibit strong expression of Ino-POU6 (Figure 8F, G), including the anterior basal and posterior basal lobes (Figure 8F, G) and the dorso-lateral and dorsal basal lobes of the supraesophageal mass (Figure 8F). The subvertical and superior frontal lobes of the vertical lobe complex also express Ino-POU6 (Figure 8I, J). Weak or no Ino-POU6-expression was detected in late prehatching developmental stages (not shown).

\section{Discussion}

\section{Four POU genes are expressed during $I$. notoides} development

In this study, four POU gene orthologs were identified in the transcriptomes derived from early developmental stages and adult CNS tissue of the pygmy squid I. notoides. The amino acid sequences of Ino-POU2, Ino-POU3, Ino-POU4 and Ino-POU6 cluster with other bilaterian POU orthologs (Figure 3 ) and are expressed in early developmental stages as revealed by in situ hybridization experiments (Figures 4, 6, 7, 8 and 5). This is in contrast to a recent EST analysis on developmental stages of the cuttlefish S. officinalis, which did not detect $P O U$ gene transcripts [28]. Given our findings and those in other studies investigating $P O U$ gene expression in mollusks, the lack of $P O U$ gene orthologs in the S. officinalis EST library may be a technical artifact rather than an actual absence of these transcripts $[23,25,26,28]$. To date, orthologs of the remaining two POU subfamilies, POU1 and POU5, have not been reported from any lophotrochozoan. POU1 appears to be ancestral while POU5 might be a vertebrate innovation $[18,50]$.

\section{Comparative expression of $I$. notoides POU genes}

Ino-POU2-expression is mainly restricted to the anlagen of the gills; the posterior mantle; and the pedal, palliovisceral and optic ganglia (Figures 4A, B and 5). Besides these expression domains, Ino-POU2 is also expressed globally in the embryo (Figure 4B,C,E). To date, no POU2-expression patterns are known for any other lophotrochozoan (Table 1). The genes PDM-1 (POU-19) and PDM-2 (POU-29) of Drosophila melanogaster possess high sequence similarity to other bilaterian POU2orthologs and are expressed in the neuroectoderm but also in peripheral sensory organs (Table 1 ). In I. notoides POU2 is only expressed in few sensory epithelia, that is, the eyes of stage 22 individuals (Figure $4 \mathrm{C}$ ). CEH-18, the 


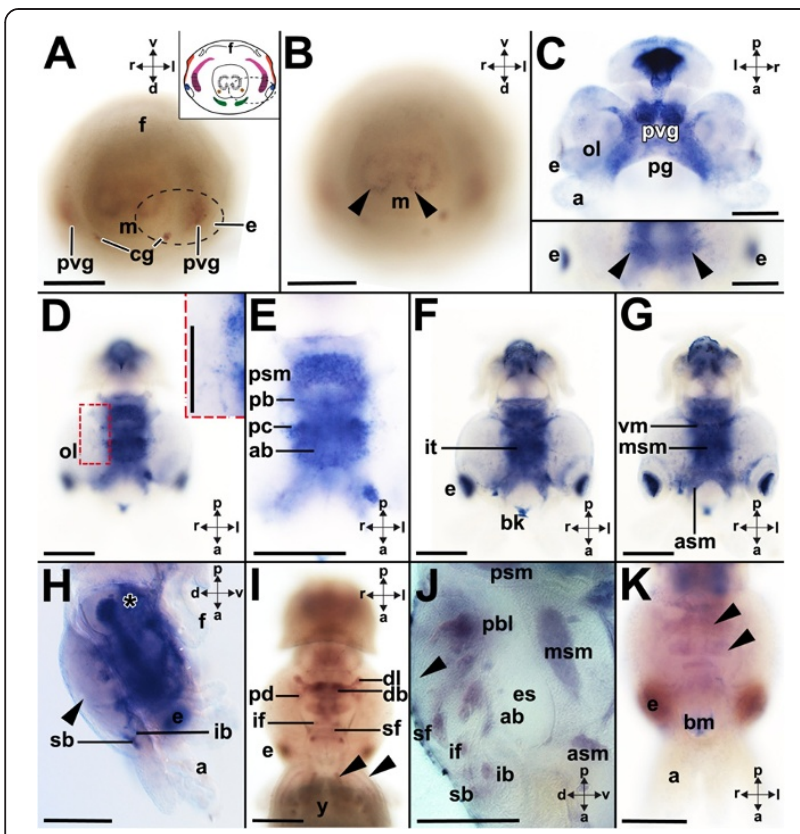

Figure 6 Ino-POU3-expression during development of $I$. notoides. The cartoon highlights Ino-POU3-expression as black checkered domains (see Figure 1 for color-coded ganglia). Dorsal (d)-ventral (v), anterior (a)-posterior (p), and left (I)-right ( $r$ ) axes indicate the orientation. Staining around shell gland is unspecific (C, D, F, G). (A) During stage 19 Ino-POU3 is expressed in the cerebral (cg) and palliovisceral ganglia (pvg). (B) Same specimen as shown in A expressing Ino-POU3 in the mantle (arrowheads). (C) Stage 22 individuals express Ino-POU3 in the pedal (pg) and palliovisceral ganglia, the eyes (e), and the anterior basal lobes (arrowheads in lower inset). D-G: Optical sections from dorsal to ventral of a stage 24 individual (unspecific staining in the beak (bk)). (D) Ino-POU3 is expressed in the brain including the peduncle lobe (arrowhead in inset). (E) Close-up of the supraesophageal and posterior subesophageal masses (psm). The anterior basal (ab), posterior basal (pb), and precommissural lobes (pc) express Ino-POU3. (F) The interbasal lobes (it) connect to the subesophageal mass and express Ino-POU3. (G) Ino-POU3-expression in the anterior (asm) and middle subesophageal masses ( $\mathrm{msm}$ ) and in the ventral magnocellular lobes (vm). (H) Ino-POU3-expression in the superior (sb) and inferior buccal lobes (ib) but not in the vertical lobe complex (arrowhead) during stage 25. The statocysts are labeled with an asterisk. (I) During stage 25 Ino-POU3 is expressed in the intrabrachial ganglia (arrowheads), the dorso-lateral (dl), the peduncle (pd), the superior frontal (sf) and inferior frontal lobes (if) (J) During stage 26 Ino-POU3 is expressed in the brain including the inferior buccal (ib) and superior buccal lobes (sb) but not the vertical and subvertical lobes (arrowhead). (K) Weak Ino-POU3expression during stage 27. Abbreviations: $a$, arm; bm, buccal mass; es, esophagus; f, funnel; m, mantle; ol, optic lobe. Scale bars: A-G: $150 \mu \mathrm{m}, \mathrm{H}-\mathrm{K}: 200 \mu \mathrm{m}$.

nematode POU2 ortholog, is expressed in muscles and the epidermis of developmental stages and in the gonadal sheath cells of adults (Table 1 ). In vertebrates such as the frog Xenopus laevis and the rat Rattus norvegicus POU2 orthologs are expressed in the anterior brain region during development (Table 1). This is in contrast to I. notoides with POU2 being expressed in the pedal and palliovisceral ganglia, which are located in the posterior region of the CNS (present study). Early expression in both these ganglia suggests that POU2 is involved in the establishment of these brain regions. Stage 25 to 27 individuals express Ino-POU2-throughout the CNS, an expression pattern that resembles patterns of all other POU genes in these late prehatching developmental stages.

Although there is only limited information on the expression of $P O U$ genes in lophotrochozoan taxa, POU3expression has been documented for a vetigastropod, the tropical abalone $H$. asinina [24,25]. In the abalone trochophore, Has-POU3 transcripts are present in two large posterior cells (possibly mucus cells) and two smaller antero-lateral cells in the anlage of the foot ectoderm [25]. In I. notoides, the first POU3-expressing cells are located in the anlagen of the cerebral and palliovisceral ganglia of stage 19 individuals (Figures 6A and 5). In addition, two circular expression domains, which are not associated with the shell gland, are located in the embryonic mantle ectoderm (Figure 6B). Post-torsional veligers of $H$. asinina are the first to express Has-POU3 in all ganglia of the developing adult CNS, that is, the pleuropedal, cerebral, esophageal, and branchial ganglia [25]. A more gradual increase of POU3-expression can be observed in the ganglia and brain lobes of I. notoides. Stage 22 individuals first express Ino-POU 3 in the palliovisceral and pedal ganglia and subsequently in increasing domains of the supraesophageal brain lobes. POU3 expression in the cerebral ganglia of $H$. asinina and the supraesophageal mass of I. notoides supports the traditional view that these brain regions are homologous [51]. Homology has also been claimed for the gastropod pedal ganglia and the cephalopod subesophageal mass, which each express POU3. $H$. asinina, as well as $I$. notoides, express POU3 in their cephalic appendages, that is, the gastropod tentacles [24] and the cephalopod intrabrachial ganglia of stage 25 individuals (arrowheads in Figure 6I). Notably, Ino-POU3-expression in the CNS ceases in the late prehatching stages of I. notoides (c.f. Figure $6 \mathrm{~J}, \mathrm{~K})$, resembling the condition in $H$. asinina where no Has-POU3-transcripts were observed in the CNS but in were observed in different expression domains such as the dorsoposterior visceral mass, the presumptive anlagen of the radula sac, and the statocysts [25]. Adult abalone express $P O U 3$ in their cerebral and pleuropedal ganglia but also the epipodial tentacles, the tentacles, eyes, gills, and muscles [24]. Stage 22 individuals of $I$. notoides also strongly express POU3 in their eyes (Figure $6 \mathrm{C}$ ). In adult I. notoides, POU3, as well as all other identified $P O U$ genes, are expressed in brain tissue as revealed by transcriptome screens; however, the individual expression levels are unknown. 


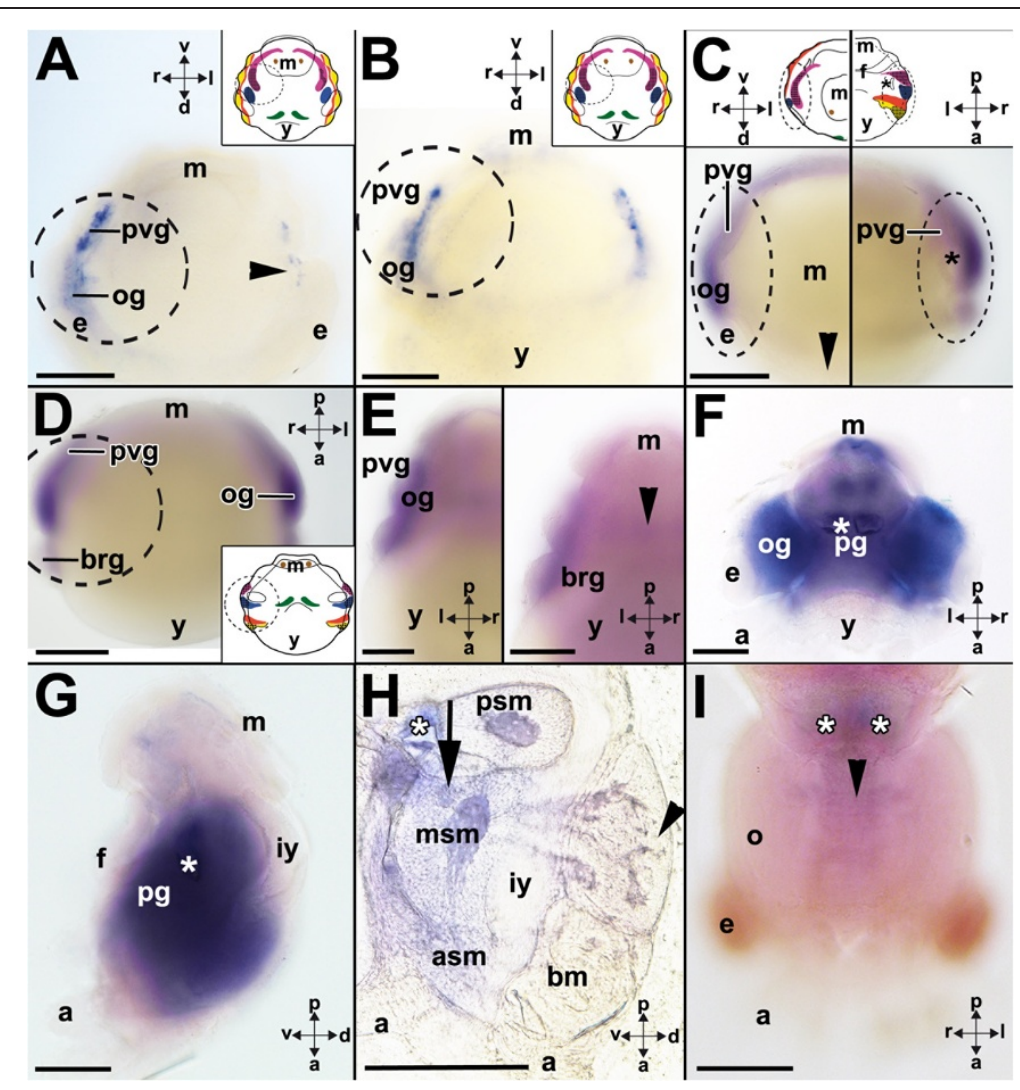

Figure 7 Ino-POU4-expression during development of I. notoides. Cartoons highlight Ino-POU4-expression as black checkered domains (see Figure 1 for color-code of ganglia). Dorsal (d)-ventral (v), anterior (a)-posterior (p), and left (I)-right (r) axes indicate the orientation. (A) Stage 19 individuals exhibit Ino-POU4-expression in the palliovisceral (pvg) and optic ganglia (og) close to the eyes (e) (dorsoposterior view). In this specimen, Ino-POU4 staining is weaker on the left side (arrowhead) than on the right side. (B) During stage 19 Ino-POU4 is expressed in the palliovisceral and optic ganglia (dorsoposterior view). (C) Stage 20 individuals exhibit Ino-POU4-expression in the optic and palliovisceral ganglia (dorsoposterior view). Note the absence of Ino-POU4 expression in the cerebral ganglia (arrowhead). (D) The optic, palliovisceral, and intrabrachial ganglia (brg) of stage 20 individuals express Ino-POU4. (E) Stage 21 individuals exhibit Ino-POU4 expression in the palliovisceral and optic ganglia (left inset), the intrabrachial and the pedal ganglia (arrowhead) (right inset). (F) Stage 22 individuals exhibit strong Ino-POU4-expression in the optic ganglia as well as in the palliovisceral and pedal ganglia (pg). No Ino-POU4 is expressed in the intrabrachial ganglia of the arms (a). (G) The Ino-POU4-expression pattern of stage 23 individuals resembles that of stage 22 individuals. $\mathbf{( H )}$ Vibratome section along the midline of the cephalic region during stage 25. Note the lack of Ino-POU4-expression in the vertical lobe (arrowhead). Besides the anterior (asm), middle (msm), and posterior subesophageal (psm) and supraesophageal mass, also the ventral magnocellular lobes (arrow) express Ino-POU4. (I) Stage 27 individuals exhibit only faint Ino-POU4-expression in the posterior basal lobes (arrowhead) and expression patterns of subsequent developmental stages resembles the one of stage 27 specimens. Abbreviations: bm, buccal mass; f, funnel; iy, internal yolk; m, mantle; $y$, yolk. The statocysts are marked by asterisks. Scale bars: A-G: $150 \mu \mathrm{m}, \mathrm{H}-\mathrm{l}: 200 \mu \mathrm{m}$.

Ino-POU4 is predominantly expressed in the CNS during early development of $I$. notoides. The first expression domains are the anlagen of the palliovisceral and optic ganglia (Figures $7 \mathrm{~A}, \mathrm{~B}$ and 5). Subsequently, the arms also express Ino-POU4. It has been proposed that POU4 orthologs may play a role during the differentiation process of distinct populations of sensory cells in a variety of bilaterians (Table 1; $[19,39]$ ). In I. notoides the only Ino-POU4 expression domain that bears vast numbers of sensory cells are the anlagen of the arms, which cease to express Ino-POU4 during subsequent development (cf. Figure 7D,G). Post-torsional larvae of $H$. asinina also express Has-POU4 in both developing cephalic tentacles
[26]. In $H$. asinina, few cell somata express Has-POU4 in the presumptive anlage of the central posterior foot of the trochophore and the anterior central foot anlage of the veliger larva, regions with high abundances of chemoand mechanoreceptors [26]. Post-torsional animals retain expression in the ventral ectoderm of the foot but also express Has-POU4 in presumptive anlagen of the eyes and in the vicinity of the esophageal ganglia [26]. In I. notoides Ino-POU4 transcripts have not been located in the eyes but in the optic ganglia of stage 19 to 23 individuals (Figure 7A,B,C,D,E and F). Other sensory expression domains comprise the statocysts and the ctenidial and osphradial rudiment in late veliger larvae of the gastropod 


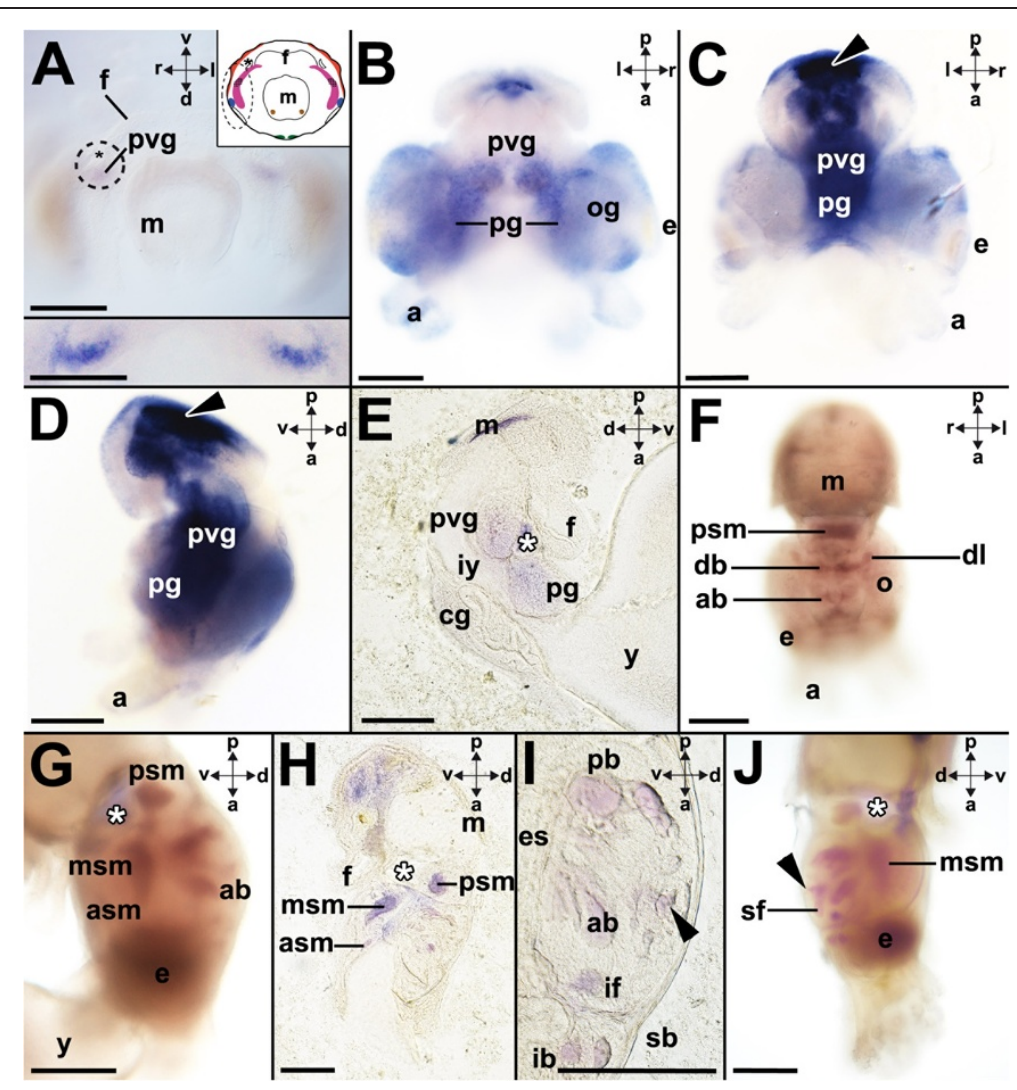

Figure 8 Ino-POU6-expression during development of I. notoides. Cartoons highlight Ino-POU6-expression as black checkered domains (see Figure 1 for color-coded ganglia). Dorsal (d)-ventral (v), anterior (a)-posterior (p), and left (I)-right ( $r$ ) axes indicate the orientation. (A) Ino-POU6expression in the palliovisceral ganglia (pvg) during stage 19. Inset: Close-up of both palliovisceral ganglia. (B) Ino-POU6-expression in the pedal (pg) and palliovisceral ganglia during stage 22. (C) During stage 23 Ino-POU6 is expressed in the pedal and palliovisceral ganglia (unspecific staining around shell gland (arrowhead)). (D) Ino-POU6-expression in the pedal and palliovisceral ganglia during stage 23 (unspecific staining around shell gland (arrowhead)). (E) Vibratome section along the midline of a stage 23 individual with Ino-POU6 being expressed in the pedal and palliovisceral ganglia but not in the cerebral ganglia (cg). (F) During stage 25 Ino-POU6 is expressed in the posterior subesophageal mass (psm), the anterior basal (ab) and posterior basal lobes including the dorso-lateral ( $\mathrm{dl}$ ) and dorsal basal lobes (db) but not the optic lobes (o). (G) During stage 25 Ino-POU6 is expressed in the brain including the anterior (asm), middle (msm), and posterior subesophageal masses. (H) Ino-POU6expression during stage 26 resembles that observed during stage 25 (vibratome section). (I) Ino-POU6-expression in the supraesophageal mass during stage 26 including the subvertical (arrowhead), the anterior basal (ab) and posterior basal lobes (pb), the inferior frontal (if), the inferior buccal (ib) and the superior buccal lobes (sb) (vibratome section). (J) During stage 27 Ino-POU6 is expressed among others in the subvertical lobe (arrowhead) and superior frontal lobe (sf). Subsequent prehatching stages cease to express Ino-POU6 in their CNS. Abbreviations: a, arm; e, eye; f, funnel; iy, internal yolk; m, mantle; og, optic ganglion; y, yolk. The statocysts are labeled by asterisks. Scale bars: A-E and I: $150 \mu \mathrm{m}, \mathrm{F}-\mathrm{H}$ and J: $200 \mu \mathrm{m}$.

H. asinina [26]. In P. dumerilii, POU4 is expressed in cells of the developing parapodia, probably belonging to the parapodial ganglia (Table 1, [27]). These findings demonstrate that at least POU 3 and POU4 are involved in the formation of the peripheral nervous system of the lophotrochozoan species investigated.

During early development Ino-POU6 is first expressed in the palliovisceral ganglia (Figure 5). In subsequent developmental stages, expression extends to the pedal ganglia and finally the supraesophageal mass (Figures 8 and 5). Although POU6-orthologs are known from other protostome invertebrates, no expression patterns have been published so far for lophotrochozoan representatives (Table 1). The adult hydrozoan C. sowerbyi expresses POU6 in the statocysts and gonads (Table $1 ;[31]) . B R N-5$, the POU6 ortholog of the rat, is intensely expressed in the developing CNS and spinal cord; however adults express $B R N-5$ in the kidney, lungs, heart, testis, pituitary gland as well as the brain (Table $1 ;[33,46])$. As stated for all other Ino-POU genes, Ino-POU6 expression levels decrease in late prehatching individuals (that is, stage 27 to 30). This resembles the situation in the developing rat brain in which transcript levels of POU6 decrease from embryonic day 15 to postnatal day 10 [46].

\section{The role of POU genes in CNS development}

A major similarity between the CNS of animals as different as rodents, fruit flies, and pygmy squids is the expression of 
POU genes in the anteriormost brain region [33], (present study). The fruit fly's protocerebrum + deuterocerebrum, the murine telencephalon + diencephalon + mesencephalon, and the gastropod and cephalopod cerebral ganglia express $P O U$ genes but lack anterior $H O X$ gene expression (Table $1 ;[33,52-56])$. This indicates that in these bilaterian representatives, $P O U$ transcription factors are involved in the development of the anteriormost neural territories, which are unlikely to be homologous according to anatomical and ontogenetic evidence and currently accepted phylogenies [57]. However, more gene expression patterns of basal representatives of various bilaterian clades, as well as expression patterns of potential bilaterian sister groups such as acoels or cnidarians, are needed to assess their role during development $[57,58]$.

The present study demonstrates that at least four POU genes are expressed during early cephalopod CNS development and in the adult CNS. All major ganglia exhibit unique expression patterns in early embryos, indicating different roles during the establishment of these brain regions (Figure 5). In subsequent prehatching developmental stages all four $P O U$ genes are intensely expressed in wide parts of the brain; however, expression of all $P O U$ genes ceases in late prehatching embryos (approximately stage 27 to 30). Interestingly, only few of the investigated POU genes are expressed in the optic lobes, and peripheral ganglia such as the intrabrachial ganglia only express few $P O U$ orthologs in a small developmental time frame. Further expression analyses on $P O U$ genes and other homeobox genes in other molluscan representatives will also contribute to our knowledge on the role of these genes during development in lophotrochozoans.

\section{Conclusions}

All four Ino-POU genes are expressed in unique spatiotemporal combinations during early neurogenesis, which indicates that they are involved in distinct processes during early brain development. As reported for other phylogenetically distantly related bilaterians, expression is associated with anteriormost neural structures, which are unlikely to be homologous. POU3 and POU4 are the only POU genes within lophotrochozoans that have been comparatively studied. Since their expression patterns are broadly similar, the increased complexity of the cephalopod brain might be due to other unknown factors.

\footnotetext{
Abbreviations

a: arm; a: anterior (in the orientation axes); aa: amino acid; ab: anterior basal lobe; asm: anterior subesophageal mass; bk: beak; BLAST: basic local alignment search tool; bm: buccal mass; bp: base pairs; brg: intrabrachial ganglion; cDNA: complementary deoxyribonucleic acid; cg: cerebral ganglion; CNS: central nervous system; d: dorsal; db: dorsal basal lobe; DIG: digoxigenin-11-uridin-triphosphate; dl: dorso-lateral lobe; e: eye; es: esophagus; f: funnel; EST: expressed sequence tags; ib: inferior buccal lobe; if: inferior frontal lobe; it: interbasal lobe; iy: internal yolk; l: left; m: mantle; mo: mouth; msm: middle subesophageal mass; NCBI: national center for biotechnology information; o: optic lobe; og: optic ganglion;
}

p: posterior; pb: posterior basal lobe; pvg: palliovisceral ganglion; PBS: phosphate buffered saline; PBT: phosphate buffered saline $+0.1 \%$ TritonX; pc: precommissural lobe; pd: peduncle lobe; pg: pedal ganglion; PNS: peripheral nervous system; psm: posterior subesophageal mass; r: right; RNA: ribonucleic acid; RNAseq: ribonucleic acid sequencing; rRNA: ribosomal ribonucleic acid; RT-PCR: reverse transcription polymerase chain reaction; sb: superior buccal lobe; sf: superior frontal lobe; sg: stellate ganglion; spm: supraesophageal mass; v: ventral; vm: ventral magnocellular lobe; y: yolk.

\section{Competing interests}

The authors declare that they have no competing interests.

\section{Authors' contributions}

TW designed the project with AW and BMD. TW and CMD performed the phylogenetic analysis. TW carried out the experiments, analyzed the data, and drafted the manuscript. AW contributed to writing of the manuscript. All authors read and approved the final version of the manuscript.

\section{Acknowledgements}

Sonia Victoria Rodríguez Monje is thanked for carrying out some of the in situ hybridization experiments. TW thanks Thomas Eder and Thomas Rattei (both in Vienna) for their kind help with the Illumina transcriptome assembly. The authors thank two anonymous reviewers for their comments. This work was supported by grants to BMD from the Australian Research Council. Research in the lab of AW was kindly supported by generous support of the Faculty of Life Sciences, University of Vienna.

\section{Author details}

'Department of Integrative Zoology, Faculty of Sciences, University of Vienna, Althanstr. 14, 1090 Vienna, Austria. ${ }^{2}$ School of Biological Sciences, The University of Queensland, Brisbane QLD 4072, Australia.

Received: 22 July 2014 Accepted: 29 September 2014 Published: 5 November 2014

\section{References}

1. Wells MJ: Octopus, Physiology and Behavior of an Advanced Invertebrate. London: Chapman and Hall; 1978.

2. Cummins SF, Boal JG, Buresch KC, Kuanpradit C, Sobhon P, Holm JB, Degnan BM, Nagle GT, Hanlon RT: Extreme aggression in male squid induced by a $\beta$-MSP-like pheromone. Curr Biol 2011, 21:322-327.

3. Romagny S, Darmaillacq AS, Guibé M, Bellanger C, Dickel L: Feel, smell and see in an egg: emergence of perception and learning in an immature invertebrate, the cuttlefish embryo. J Exp Biol 2012, 215:4125-4130.

4. Young JZ: The Anatomy of the Nervous System of Octopus vulgaris. Oxford: Clarendon; 1971.

5. Meister G: Organogenese von Loligo vulgaris LAM. Mollusca, Cephalopoda, Teuthoidea, Myopsida, Loliginidae. Zool Jb Anat 1972, 89:247-300.

6. Marquis VF: Die Embryonalentwicklung des Nervensystem von Octopus vulgaris Lam. (Cephalopoda, Octopoda), eine histologische Analyse. Verhandl Naturf Ges Basel 1989, 99:23-76.

7. Shigeno S, Tsuchiya K, Segawa S: Embryonic and paralarval development of the central nervous system of the loliginid squid Sepioteuthis lessoniana. J Comp Neurol 2001, 437:449-475.

8. Yamamoto M, Shimazaki Y, Shigeno S: Atlas of the embryonic brain in the pygmy squid, Idiosepius paradoxus. Zoolog Sci 2003, 20:163-179.

9. Shigeno S, Takenori S, Moritaki T, Kasugai T, Vecchione M, Agata K Evolution of the cephalopod head complex by assembly of multiple molluscan body parts: Evidence from Nautilus embryonic development. J Morphol 2008, 69:1-17.

10. Nixon M, Young JZ: The Brains and Lives of Cephalopods. New York: Oxford University Press; 2003.

11. Baratte $S$, Bonnaud L: Evidence of early nervous differentiation and early catecholaminergic sensory system during Sepia officinalis embryogenesis. J Comp Neurol 2009, 517:539-549.

12. Wollesen T, Cummins SF, Degnan BM, Wanninger A: FMRFamide gene and peptide expression during central nervous system development of the cephalopod mollusk, Idiosepius notoides. Evol Dev 2010, 12:113-130. 
13. Wollesen T, Degnan BM, Wanninger A: Expression of serotonin (5-HT) during CNS development of the cephalopod mollusk, Idiosepius notoides. Cell Tissue Res 2010, 342:161-718.

14. Aroua S, Andouche A, Martin M, Baratte S, Bonnaud L: FaRP cell distribution in the developing CNS suggests the involvement of FaRPs in all parts of the chromatophore control pathway in Sepia officinalis (Cephalopoda). Zoology 2011, 114:113-122.

15. Wollesen T, Nishiguchi MK, Seixas P, Degnan BM, Wanninger A: The VD1/ RPD2 a1-neuropeptide is highly expressed in the brain of cephalopod mollusks. Cell Tissue Res 2012, 348:439-452.

16. Wollesen T, Sukhsangchan C, Seixas P, Nabhitabhata J, Wanninger A Analysis of neurotransmitter distribution in brain development of benthic and pelagic octopod cephalopods. J Morphol 2012, 273:776-790.

17. Herr W, Sturm RA, Clerc RG, Corcoran LM, Baltimore D, Sharp PA, Ingraham HA, Rosenfeld MG, Finney M, Ruvkun G, Horvitz HR: The POU domain: a large conserved region in the mammalian pit-1, oct-1, oct-2, and Caenorhabditis elegans unc-86 gene products. Genes Dev 1988, 2:1513-1516.

18. Larroux C, Luke GN, Koopman P, Rokhsar DS, Shimeld SM, Degnan BM: Genesis and expansion of metazoan transcription factor gene classes. Mol Biol Evol 2008, 25:980-996.

19. Veenstra GJC, van der Vliet PC, Destrée $\mathrm{OHJ}$ : POU domain transcription factors in embryonic development. Mol Biol Rep 1997, 24:139-155.

20. Ryan AK, Rosenfeld MG: POU domain family values: flexibility, partnerships, and developmental codes. Genes Dev 1997, 11:1207-1225.

21. Orii H, Agata K, Watanabe K: POU-domain genes in planarian Dugesia japonica: the structure and expression. Biochem Biophys Res Commun 1993, 192:1395-1402.

22. Muñoz-Mármol AM, Casali A, Miralles A, Bueno D, Bayascas JR, Romero R, Saló E: Characterization of platyhelminth POU domain genes: ubiquitous and specific anterior nerve cell expression of different epitopes of GtPOU-1. Mech Dev 1998, 76:127-140.

23. Lozano V, Martínez-Escauriaza R, Bernardo-Castiñeira C, Mesías-Gansbiller C, Pazos AJ, Sánchez JL, Pérez-Parallé ML: A novel class of Pecten maximus POU gene, PmaPOU-IV: characterization and expression in adult tissues. J Exp Mar Biol Ecol 2014, 453:154-161.

24. O'Brien EK, Degnan BM: Expression of POU, Sox, and Pax genes in the brain ganglia of the tropical abalone Haliotis asinina. Mar Biotechnol 2000, 2:545-557.

25. O'Brien EK, Degnan BM: Pleiotropic developmental expression of HasPOU-III, a class III POU gene, in the gastropod Haliotis asinina. Mech Dev 2002, 114:129-132.

26. O'Brien EK, Degnan BM: Developmental expression of a class IV POU gene in the gastropod Haliotis asinina supports a conserved role in sensory cell development in bilaterians. Dev Genes Evol 2002, 212:394-398.

27. Backfisch B, Veedin Rajan VB, Fischer RM, Lohs C, Arboleda E, Tessmar-Raible K Raible F: Stable transgenesis in the marine annelid Platynereis dumerilii sheds new light on photoreceptor evolution. Proc Natl Acad Sci U S A 2013, 110:193-198.

28. Bassaglia Y, Bekel T, Da Silva C, Poulain J, Andouche A, Navet S, Bonnaud L: ESTs library from embryonic stages reveals tubulin and reflectin diversity in Sepia officinalis (Mollusca-Cephalopoda). Gene 2012, 498:203-211.

29. Lemaire J: Table de developpement embryonnaire de Sepia officinalis. L. (Mollusque Céphalopode). Bull Soc Zool 1970, 95:773-782.

30. Ramachandra NB, Gates RD, Ladurner P, Jacobs DK, Hartenstein V: Embryonic development in the primitive bilaterian Neochildia fusca: normal morphogenesis and isolation of POU genes Brn-1 and Brn-3. Dev Genes Evol 2002, 212:55-69.

31. Hroudova M, Vojta P, Strnad H, Krejcik Z, Ridl J, Paces J, Vlcek C, Paces V: Diversity, phylogeny and expression patterns of Pou and Six homeodomain transcription factors in hydrozoan jellyfish Craspedacusta sowerbyi. PLoS One 2012, 7:e36420

32. Nakanishi N, Yuan D, Hartenstein V, Jacobs DK: Evolutionary origin of rhopalia: insights from cellular-level analyses of Otx and POU expression patterns in the developing rhopalial nervous system. Evol Dev 2010, 12:404-415

33. Treacy MN, Rosenfeld MG: Expression of a family of pou-domain protein regulatory genes during development of the central nervous system. Annu Rev Neurosci 1992, 15:139-165.

34. Dick T, Yang XH, Yeo SL, Chia W: Two closely linked Drosophila POU domain genes are expressed in neuroblasts and sensory elements. Proc Natl Acad Sci USA 1991, 88:7645-7649.
35. Anderson MG, Perkins GL, Chittick P, Shrigley RJ, Johnson WA: drifter, a Drosophila POU-domain transcription factor, is required for correct differentiation and migration of tracheal cells and midline glia. Genes Dev 1995, 9:123-137.

36. Finney M, Ruvkun $\mathrm{G}$, Horvitz HR: The $\mathrm{C}$. elegans cell lineage and differentiation gene unc-86 encodes a protein with a homeodomain and extended similarity to transcription factors. Cell 1988, 55:757-769.

37. Finney M, Ruvkun G: The unc-86 gene product couples cell lineage and cell identity in C. elegans. Cell 1990, 63:895-905.

38. Greenstein D, Hird S, Plasterk RH, Andachi Y, Kohara Y, Wang B, Finney M, Ruvkun G: Targeted mutations in the Caenorhabditis elegans POU homeobox gene ceh-18 cause defects in oocyte cell cycle arrest, gonad migration, and epidermal differentiation. Genes Dev 1994, 8:1935-1948.

39. Candiani S, Pennati R, Oliveri D, Locascio A, Branno M, Castagnola P, Pestarino M, De Bernardi F: Ci-POU-IV expression identifies PNS neurons in embryos and larvae of the ascidian Ciona intestinalis. Dev Genes Evol 2005, 215:41-45.

40. Candiani S, Oliveri D, Parodi M, Bertini E, Pestarino M: Expression of AmphiPOU-IV in the developing neural tube and epidermal sensory neural precursors in amphioxus supports a conserved role of class IV POU genes in the sensory cells development. Dev Genes Evol 2006, 216:623-633.

41. Candiani S, Castagnola P, Oliveri D, Pestarino M: Cloning and developmental expression of AmphiBrn1/2/4, a POU III gene in amphioxus. Mech Dev 2002, 116:231-234.

42. Spaniol P, Bornmann C, Hauptmann G, Gerster T: Class III POU genes of zebrafish are predominantly expressed in the central nervous system. Nucleic Acids Res 1996, 24:4874-4881.

43. Agarwal VR, Sato SM: XLPOU 1 and XLPOU 2, two novel POU domain genes expressed in the dorsoanterior region of Xenopus embryos. Dev Biol 1991, 147:363-373

44. Matsuo-Takasaki M, Lim JH, Sato SM: The POU domain gene, XIPOU 2 is an essential downstream determinant of neural induction. Mech Dev 1999, 89:75-85.

45. Baltzinger M, Relaix F, Remy P: Transcription of XLPOU3, a brain-specific gene, during Xenopus laevis early embryogenesis. Mech Dev 1996, 58:103-114.

46. Andersen B, Schonemann MD, Pearse RV II, Jenne K, Sugarman J, Rosenfeld MG: Brn-5 is a divergent POU domain factor highly expressed in layer IV of the neocortex. J Biol Chem 1993, 268:23390-23398.

47. Yamamoto M: Normal embryonic stages of the pygmy cuttlefish, Idiosepius pygmaeus paredoxus Ortmann. Zool Sci 1988, 5:989-998.

48. Grabherr MG, Haas BJ, Yassour M, Levin JZ, Thompson DA, Amit I, Adiconis X, Fan L, Raychowdhury R, Zeng Q, Chen Z, Mauceli E, Hacohen N, Gnirke A, Rhind A, Rhind N, di Palma F, Birren BW, Nusbaum C, Lindblad-Toh K, Friedman N, Regev A: Full-length transcriptome assembly from RNA-seq data without a reference genome. Nat Biotechnol 2011, 15:644-652.

49. Shigeno S, Yamamoto M: Organization of the nervous system in the pygmy cuttlefish, Idiosepius paradoxus Ortmann (Idiosepiidae, Cephalopoda). J Morphol 2002, 254:65-80.

50. Bürglin TR, Ruvkun G: Regulation of ectodermal and excretory function by the C. elegans POU homeobox gene ceh-6. Development 2001, 128:779-790.

51. Bullock TH: Mollusca: Cephalopoda. In Structure and Function in the Nervous Systems of Invertebrates. Edited by Bullock TH, Horridge GA. San Francisco: Freeman; 1965:1433-1515.

52. Lee PN, Callaerts P, de Couet HG, Martindale MQ: Cephalopod Hox genes and the origin of morphological novelties. Nature 2003, 424:1061-1065.

53. Samadi L, Steiner G: Involvement of Hox genes in shell morphogenesis in the encapsulated development of a top shell gastropod (Gibbula varia L.). Dev Genes Evol 2009, 219:523-530.

54. Samadi $L$, Steiner $G$ : Expression of Hox genes during the larval development of the snail, Gibbula varia (L.) - further evidence of non-colinearity in molluscs. Dev Genes Evol 2010, 220:161-172.

55. Hashimoto N, Kurita Y, Wada H: Developmental role of dpp in the gastropod shell plate and co-option of the $d p p$ signaling pathway in the evolution of the operculum. Dev Biol 2012, 366:367-373.

56. Reichert $\mathrm{H}$ : A tripartite organization of the urbilaterian brain: developmental genetic evidence from Drosophila. Brain Res Bull 2005 , 66:491-494

57. Hejnol A, Obst M, Stamatakis A, Ott M, Rouse GW, Edgecombe GD, Martinez P, Baguñà J, Bailly X, Jondelius U, Wiens M, Müller WE, Seaver E, Wheeler 
WC, Martindale MQ, Giribet G, Dunn CW: Assessing the root of bilaterian animals with scalable phylogenomic methods. Proc Biol Sci 2009, 276:4261-4270.

58. Dunn CW, Hejnol A, Matus DQ, Pang K, Browne WE, Smith SA, Seaver E, Rouse GW, Obst M, Edgecombe GD, Sørensen MV, Haddock SH, Schmidt-Rhaesa A, Okusu A, Kristensen RM, Wheeler WC, Martindale MQ, Giribet G: Broad phylogenomic sampling improves resolution of the animal tree of life. Nature 2008, 452:745-749.

doi:10.1186/2041-9139-5-41

Cite this article as: Wollesen et al:: POU genes are expressed during the formation of individual ganglia of the cephalopod central nervous system. EvoDevo 2014 5:41.

\section{Submit your next manuscript to BioMed Central and take full advantage of:}

- Convenient online submission

- Thorough peer review

- No space constraints or color figure charges

- Immediate publication on acceptance

- Inclusion in PubMed, CAS, Scopus and Google Scholar

- Research which is freely available for redistribution 